\title{
Synthesis, Structure, Photoluminescence, and Raman Spectrum of Indium Oxide Nanowires
}

\author{
H.S. Kim, H.G. NA, J.C. YAng, C. LeE, And H.W. Kim* \\ Division of Materials Science and Engineering, Inha University, Incheon 402-751, Republic of Korea \\ Production of indium oxide $\left(\mathrm{In}_{2} \mathrm{O}_{3}\right)$ whiskers at a very low temperature of $650{ }^{\circ} \mathrm{C}$ was reported. The synthetic \\ route was comprised of a thermal heating process of a mixture of In and $\mathrm{Mg}$ powders. We have investigated \\ the structural properties of the as-synthesized nanowires by using X-ray diffraction and scanning electron \\ microscopy. The product consisted of one-dimensional nanowires, with a crystalline cubic structure of $\operatorname{In}_{2} \mathrm{O}_{3}$. \\ The photoluminescence measurement with the Gaussian fitting exhibited visible light emission bands centered at \\ $2.1 \mathrm{eV}$ and $2.8 \mathrm{eV}$. The peaks of the Raman spectrum were indexed to the modes being associated with cubic $\operatorname{In}_{2} \mathrm{O}_{3}$.
}

PACS: 81.07.-b, 78.55.-m

\section{Introduction}

One-dimensional (1D) nano-scale or sub-micron scale materials are currently being exploited as active components in a wide range of technological applications. Since indium oxide $\left(\mathrm{In}_{2} \mathrm{O}_{3}\right)$ is an $n$-type semiconductor with a wide band gap, it has been extensively studied for many applications, such as photovoltaic devices, electro-optical devices, and sensors for oxidizing gases. In the present paper, we have reported the successful fabrication of $\mathrm{In}_{2} \mathrm{O}_{3}$ nanowires by the simple heating of a mixture of In and $\mathrm{Mg}$ powders at $650^{\circ} \mathrm{C}$. The successful synthesis of nanowires at a low temperature will pave the way for an efficient integration of future nanodevices with Si integrated circuit technology.

\section{Experimental}

The source material was a mixture of $\mathrm{Mg}$ and In powders. We employed standard polished p-type (100) Si substrates, with a predeposited $3 \mathrm{~nm}$ thick Au catalytic layer. In growth experiments, the quartz tube in the furnace was maintained at a temperature of $650{ }^{\circ} \mathrm{C}$ for $1 \mathrm{~h}$ with the ambient gas $\left(\mathrm{Ar}+\mathrm{O}_{2}\right)$ being at a constant total pressure of 2 Torr.

The as-prepared products were characterized by X-ray diffraction (XRD) and scanning electron microscopy (SEM). The optical properties of the product were investigated with a SPEC-1403 photoluminescence (PL) spectrometer by using a $\mathrm{He}-\mathrm{Cd}$ laser line $(325 \mathrm{~nm}, 55 \mathrm{~mW})$ as the excitation source at room temperature. Micro-Raman spectra were obtained using a Renishaw Raman spectromicroscope scanning from $100 \mathrm{~cm}^{-1}$ to $400 \mathrm{~cm}^{-1}$

\footnotetext{
* corresponding author; e-mail: hwkim@inha.ac.kr
}

at room temperature in open air. An He-Ne laser beam with a wavelength of $633 \mathrm{~nm}$ was used for the Raman excitation.

\section{Results and discussion}

Figure 1a shows the XRD pattern of the product. All intense peaks in the spectrum can be well indexed to cubic $\mathrm{In}_{2} \mathrm{O}_{3}$ (JCPDS Card No. 06-0416, space group Ia3(206), $a=10.118 \AA$ ), except for small diffraction peaks, corresponding to cubic Au (JCPDS Card No. 04-0784). Apart from the $\mathrm{Au}$, which originated from substrate, no impurities, such as unreacted In or other indium oxides, were detected. Since the angle of the incident beam to the substrate surface was about $0.5^{\circ}$ in the present XRD measurements, we surmise that the peaks are mainly from the product.

Figure 1b shows a top-view SEM image of the product on the substrate surface, exhibiting the random growth directions of the nanowires. The nanowires have a straight-line and continuous morphology along the length direction. Statistical analysis of SEM image shows that the nanowires have diameters ranging from 40 to $160 \mathrm{~nm}$. Although it is not shown in this paper, close examination reveals that the nanowires have nanoparticles at their tips. Since the nanoparticles were mainly composed of $\mathrm{Au}$ elements based on energy dispersive X-ray spectroscopy analysis, the growth mechanism of the nanowires can be understood on the basis of a vapor-liquid-solid (VLS) growth process, in which the $\mathrm{Au}$ nanoparticles (originating from the substrate) played a catalytic role. In the present case, In powders will evaporate to form In vapors. At this moment, it is not clear what is the role of $\mathrm{Mg}$. However, by conducting the same experiments without using the Mg powders, we could not get any thin nanowire. We surmise that $\mathrm{Mg}$ lowers the 
melting point of the In-Mg alloy. Accordingly, the source materials are more likely to exist as a liquid, which is favorable for the VLS process.

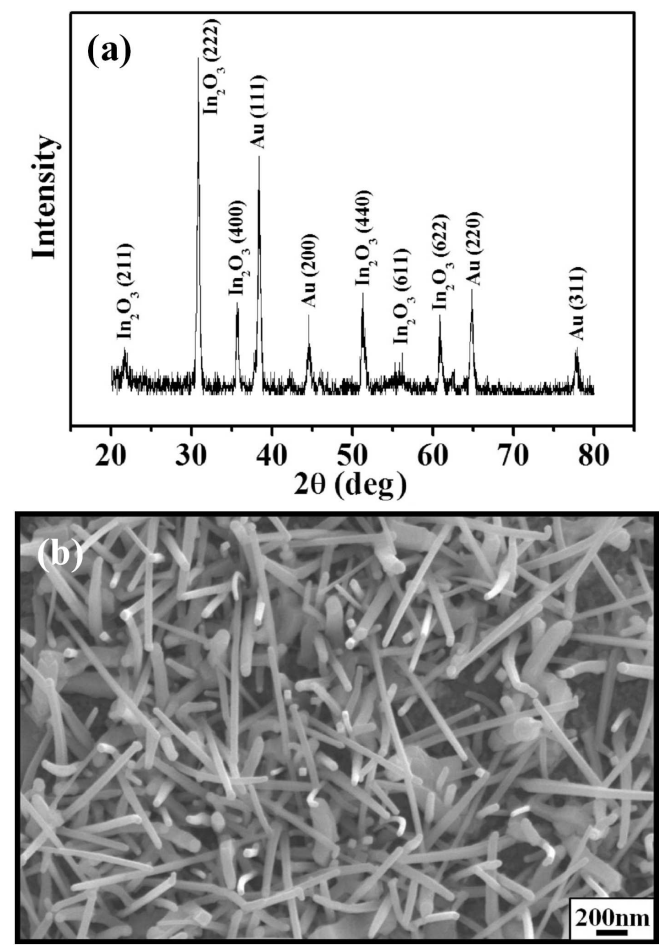

Fig. 1. (a) XRD pattern and (b) SEM image of the product synthesized at $650{ }^{\circ} \mathrm{C}$.

Figure 2 shows the PL spectrum measured at room temperature. By means of carrying out a multi-peak Gaussian fitting to two major peaks of the PL spectrum, we found that the Gaussian curves fit the original curves almost perfectly. Accordingly, the PL spectrum is comprised of two bands, peaking at approximately $2.8 \mathrm{eV}$ in blue region and $2.1 \mathrm{eV}$ in yellow-orange region, respectively.

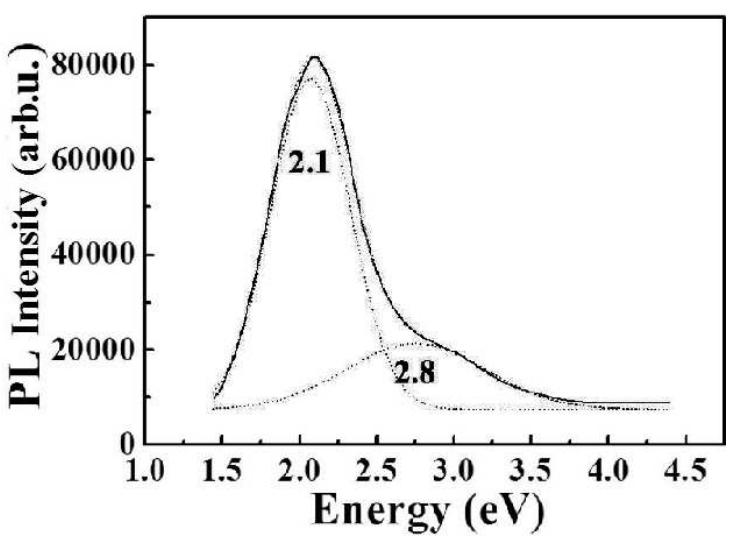

Fig. 2. Room-temperature PL spectrum of $\mathrm{In}_{2} \mathrm{O}_{3}$ nanowires.
Similar blue emission has been observed from $\operatorname{In}_{2} \mathrm{O}_{3}$ nanowires [1] and nanobelts [2], which is attributed to radiative recombination between an electron on $\mathrm{V}_{\mathrm{O}}^{\mathrm{X}}$ and a hole on $\left(\mathrm{V}_{\mathrm{In}}, \mathrm{V}_{\mathrm{O}}\right)^{\mathrm{X}}$ in the $\mathrm{In}_{2} \mathrm{O}_{3}$ nanostructures [1]. Also, the yellow-orange emission (about $2.1 \mathrm{eV}$ ) was previously observed from $\mathrm{In}_{2} \mathrm{O}_{3}$ nanotowers [3]. Jean and Her revealed that the PL emission from $\mathrm{In}_{2} \mathrm{O}_{3}$ nanostructures can be attributed from the recombination of electrons on singly ionized oxygen vacancies and holes on the valence band or double ionized oxygen vacancies [3]. In particular, the $\mathrm{In}_{2} \mathrm{O}_{3}$ nanostructures with high aspect ratio will favor the generation and existence of large quantities of oxygen vacancies [2].

Figure 3 shows the Raman spectrum of the $\mathrm{In}_{2} \mathrm{O}_{3}$ nanowires, measured at room temperature. Since cubic $\mathrm{In}_{2} \mathrm{O}_{3}$ structure belongs to the $I_{a}^{3}, T_{h}^{1}$ space group, it is known to have vibrations with symmetry $A_{\mathrm{g}}, E_{\mathrm{g}}$, and $T_{\mathrm{g}}$ (Raman active) and $T_{u}$ vibrations (IR active) [4]. The Raman shift peaks at 231 and $304 \mathrm{~cm}^{-1}$ can be ascribed to the typical $E_{\mathrm{g}}$ mode of cubic $\mathrm{In}_{2} \mathrm{O}_{3}$ [5]. Two very low frequency Raman lines at $109 \mathrm{~cm}^{-1}$ and $133 \mathrm{~cm}^{-1}$ belong to the vibrational modes of cubic $\operatorname{In}_{2} \mathrm{O}_{3}$, which agrees well with the reported values in the literature [6].

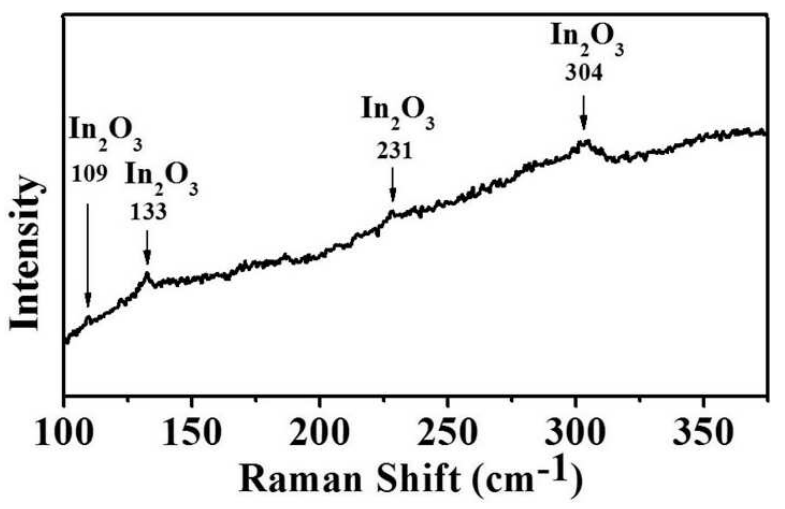

Fig. 3. Room-temperature Raman spectrum of $\operatorname{In}_{2} \mathrm{O}_{3}$ nanowires.

In conclusion, we have synthesized the $\mathrm{In}_{2} \mathrm{O}_{3}$ nanowires via heating a mixture of $\mathrm{In}$ and $\mathrm{Mg}$ powders at $650{ }^{\circ} \mathrm{C}$. SEM images indicate that the $\mathrm{In}_{2} \mathrm{O}_{3}$ nanowires have diameters in the range of $40-160 \mathrm{~nm}$. XRD spectrum reveals that the $\mathrm{In}_{2} \mathrm{O}_{3}$ nanowires have a crystalline cubic structure. A growth mechanism based on the VLS process is proposed for the formation of $\mathrm{In}_{2} \mathrm{O}_{3}$ nanowires. The PL spectrum shows a prominent visible emission bands peaked at $2.8 \mathrm{eV}$ in the blue region and $2.1 \mathrm{eV}$ in the yellow-orange region, presumably being related to the oxygen vacancies in the nanowires. The Raman peaks at 231 and $304 \mathrm{~cm}^{-1}$ are attributed to the $E_{\mathrm{g}}$ mode, whereas those at 109 and $133 \mathrm{~cm}^{-1}$ belong to the vibrational modes.

\section{Acknowledgments}

This research was supported by National Nuclear R\&D Program through the National Research Foundation of 
Korea (NRF) funded by the Ministry of Education, Science and Technology (2010-0018699).

\section{References}

[1] X.C. Wu, J.M. Hong, Z.J. Han, Y.R. Tao, Chem. Phys. Lett. 373, 28 (2003).

[2] J.S. Jeong, J.Y. Lee, C.J. Lee, S.J. Ahn, g.-C. Yi, Chem. Phys. Lett. 384, 246 (2004).

[3] S.-T. Jean, Y.-C. Her, Cryst. Growth Des. 10, 2104 (2010).
[4] O.M. Berengue, A.D. Rodrigues, C.J. Dalmaschio, A.J.C. Lanfredi, E.R. Leite, A. Chiquito, J. Phys. D, Appl. Phys. 43, 045401 (2010).

[5] J.X. Wang, H.Y. Chen, Y. Gao, D.F. Liu, L. Song, Z.X. Zhang, X.W. Zhao, X.Y. Dou, S.D. Luo, W.Y. Zhou, G. Wang, S.S. Xie, J. Cryst. Growth 284, 73 (2005).

[6] Ch.Y. Wang, Y. Dai, J. Pezoldt, B. Lu, Th. Kups, V. Cimalla, O. Ambacher, Cryst. Growth Des. 8, 1257 (2008). 